\title{
Tipología estructural de construcciones en procesos de expansión urbana*
}

\author{
Néstor Iván Rojas Gamba - Wilson Alfredo Medina Sierrab - Liby Angélica \\ Fonseca Salamancac • Giovanna Mayelle Lobaton Piñeros ${ }^{d}$
}

\begin{abstract}
Resumen: el desarrollo de la ciudad genera problemas cuando las edificaciones no se construyen cumpliendo las normativas necesarias. El objetivo del presente estudio es caracterizar la tipología estructural de edificaciones construidas en el periodo comprendido entre 1997 y 2016 en zonas representativas de la ciudad de Tunja. Para ello, se procesaron y clasificaron imágenes satelitales, delimitando zonas de desarrollo de edificaciones nuevas para el periodo de estudio. Asimismo, se analizaron datos en Sistemas de Información Geográfica (SIG), producto de encuestas del estudio de tipología estructural de las edificaciones, con el fin de determinar la calidad de las mismas. Se obtuvieron imágenes para clasificación de zonas de desarrollo y una base de datos geográfica (BDG) Con información de tipología estructural. Sobre la zona de estudio, se observaron tendencias constructivas de buena calidad orientadas, principalmente, a los sistemas de muros de carga. La interpretación de imágenes satelitales y su análisis con estudios como el de tipología estructural son útiles en la planificación del territorio. En la actualidad, referente a la ciudad, aún no se cuenta con trabajos relacionados al tema que incluyan el análisis de la información de tipología estructural.
\end{abstract}

Palabras clave: clasificación de imágenes; crecimiento urbano; edificaciones; ordenamiento territorial; tipología estructural

* Artículo de investigación.

a Ingeniero civil, magíster en Gestión de la Información y Tecnologías Geoespaciales, magíster en Geotecnia. Universidad Santo Tomás. Tunja, Colombia. Correo electrónico: nestor.rojas@usantoto.edu.co ORCID: http://orcid.org/0000-0002-9151-719X

b Ingeniero civil, especialista en Estructuras, especialista en Gestión Ambiental. Universidad Santo Tomás. Tunja, Colombia. Correo electrónico: wilson.medina@usantoto.edu.co ORCID: http://orcid.org/0000-0002-0454-3251

c Arquitecta, magíster en Gestión de la Información y Tecnologías Geoespaciales. Universidad de Boyacá. Tunja, Colombia. Correo electrónico: lafonseca@uniboyaca.edu.co ORCID: http://orcid.org/0000-0002-6364-6218

d Arquitecta, especialista en Planeación y Gestión del Desarrollo Territorial, magíster en Planificación Territorial y Gestión Ambiental. Gobernación de Boyacá. Tunja, Colombia. Correo electrónico: giovanna.lobaton@planeacionboyaca.gov.co ORCID: http://orcid.org/0000-0002-7816-5492 
Recibido: 05/05/2021

Aceptado: $13 / 09 / 2021$

Disponible en línea: 31/12/2021.

Cómo citar: N. I. Rojas Gamba, W. A. Medina Sierra, L. A. Fonseca Salamanca, y G. M. Lobaton Piñeros, «Tipología estructural de construcciones en procesos de expansión urbana», Cien.Ing.Neogranadina, vol. 31, n.` 2, pp. 93-104, dic. 2021.

\section{Structural Typology of Buildings in Urban Expansion Processes}

Abstract: The development of cities causes problems when buildings are not erected in compliance with the necessary regulations. This study aims to characterize the structural typology of buildings built between 1997 and 2016 in representative areas of Tunja, Boyacá (Colombia). For this, satellite images were processed and classified, delimiting new building development areas for the study period. We also analyzed data in Geographic Information Systems (GIS) from surveys of the structural typology study of buildings to determine their quality. Images for the classification of development areas and a geographic database (GDB) with information on structural typology were obtained. In the study area, we observed good quality construction trends, mainly oriented to load-bearing wall systems. The interpretation and analysis of satellite images with studies such as structural typology are helpful for land planning. There is still no research on the subject that includes the analysis of structural typology information for this city.

Keywords: Image classification; urban growth; buildings; land use planning; structural typology 


\section{Introducción}

Tunja es capital del departamento de Boyacá en Colombia. Fue fundada sobre la ciudad aborigen de Hunza [1], por Gonzalo Suárez Rendón, el 6 de agosto de 1539. En ese momento, se generó una ruptura en la evolución indígena existente para dar paso a la modernidad traída por los españoles [2]. De acuerdo con Hidalgo [3], la fundación de la ciudad se dio bajo la configuración de una retícula de damero, la cual era muy común en ciudades de la colonia española. La ciudad se encuentra sobre la cordillera de los Andes originada por la colisión de las placas Caribe, Nazca y Suramericana. Esta ubicación ocasiona fallas con tendencia de orientación noreste-suroeste y clasifica a la ciudad dentro de una zona de amenaza sísmica intermedia [4]. La zona urbana de Tunja se encuentra sobre una estructura de sinclinal que genera una cuenca alargada de sedimentación aluvial y fluviolacustre. La zona está compuesta, principalmente, por suelos finos de consistencia blanda, alta compresibilidad e intercalaciones de arena en ocasiones licuables [5]. Sobre los flancos del sinclinal, se presentan escarpes, laderas fuertemente inclinadas y cambios abruptos de pendiente, carcavamiento y rellenos antrópicos que pueden ser críticos para la amplificación de ondas sísmicas por efectos topográficos [6].

Desde la creación de la ciudad, se ha tenido un crecimiento en el área urbana bastante importante. Según Rincón [7], existen varias etapas en el crecimiento urbano de la ciudad: la ciudad compacta, colonial (1539-1815), lineal (1816-1920), dispersa (1920-1970) y la ciudad fragmentada (1970-2005). Estas presentan procesos de transformación por épocas de tiempo con distintas condiciones de crecimiento. Rincón también realiza proyecciones y análisis para el periodo comprendido entre los años 2005 a 2035. Para los cuales se espera que el crecimiento de Tunja presente una gran transformación; con una expansión que triplicará su área en el periodo señalado [7]. Lo anterior, exigirá de adecuadas políticas de control y consolidación urbana. El mismo estudio también realiza un análisis de la expansión urbana de Tunja entre los años 1908 y 2005. A diferencia del presente estudio, en él se registra el aumento de área urbanizada por cada periodo de tiempo y se evidencia un crecimiento importante para la ciudad, como se evidencia en la tabla 1.

Tabla 1. Expansión urbana Tunja 1900-2005

\begin{tabular}{llll}
$\begin{array}{l}\text { Periodo } \\
\text { (años) }\end{array}$ & Hectáreas (Ha) & $\begin{array}{l}\text { Crecimiento } \\
(\%)\end{array}$ & $\begin{array}{l}\text { Crecimiento } \\
\text { (Ha/año) }\end{array}$ \\
\hline $1908-1939$ & 137,7 & 142,1 & 4,3 \\
\hline $1940-1953$ & 126,2 & 54,2 & 9,0 \\
\hline $1954-1964$ & 142,3 & 47,7 & 12,9 \\
\hline $1965-1973$ & 359,5 & 71,2 & 39,9 \\
\hline $1974-1984$ & 266,4 & 23,6 & 24,2 \\
\hline $1985-1995$ & 315,8 & 28,1 & 28,7 \\
\hline $1996-2005$ & 259,9 & 17,7 & 26,0 \\
\hline
\end{tabular}

Fuente: modificado de Milena Rincón, 2009 [7].

En otro estudio, Hidalgo [3] realiza una reconstrucción del crecimiento de la periferia de la ciudad de Tunja entre 1907 y 2005 con base en aerofotografías históricas, un plano antiguo de 1907 y un plano de la morfología reciente. Dicho estudio genera el mapa de crecimiento para los años de 1907, 1939, 1957, 1973, 1989, 1996 y 2005, el cual se presenta en la figura 1.

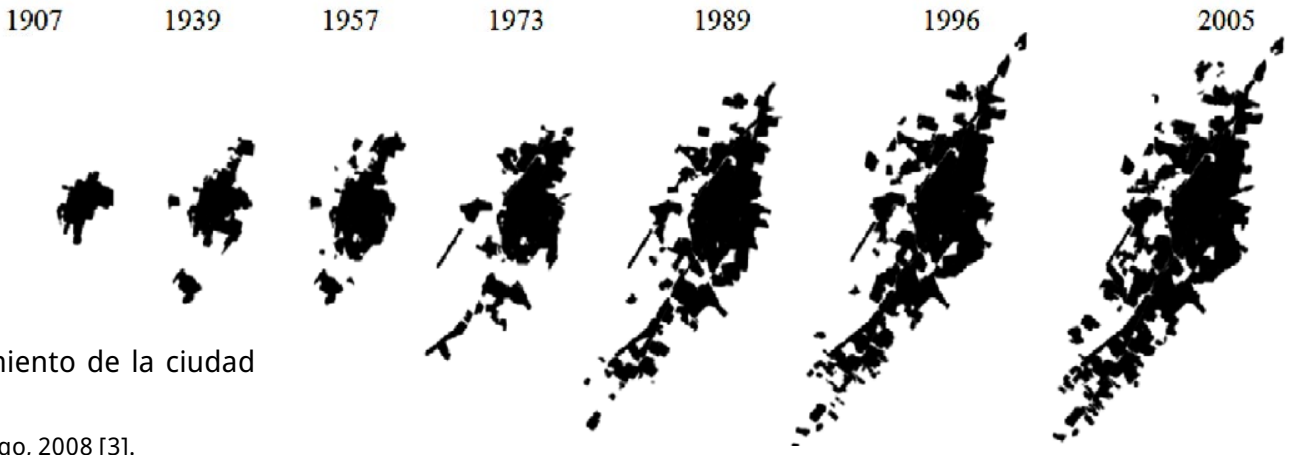

Figura 1. El crecimiento de la ciudad en el siglo XX.

Fuente: Adriana Hidalgo, 2008 [3]. 
El crecimiento urbano requiere el análisis de políticas y marcos legales que generen proyectos para la planificación. En 2021, la Organización para las Naciones Unidas mediante su programa onu-Habitat, Por un mejor futuro Urbano, evaluó dichas políticas de planeación urbana para Colombia, y encontraron, como una de las prioridades, reducir los gases de efecto invernadero a través de la planificación y la forma urbana [8].

Lo anterior, se relaciona directamente con la cuantificación, caracterización y análisis de procesos de expansión urbana que afectan directamente la sostenibilidad ambiental [9]. Dichos análisis contribuyen al cumplimiento de Objetivos de Desarrollo Sostenible (oDs). Especialmente, el relacionado con "Ciudades y Comunidades Sostenibles" [10]. La expansión urbana de la ciudad debe tener en cuenta los procesos constructivos. Un estudio de tipología estructural caracteriza las edificaciones de una zona de estudio y puede evidenciar la presencia de problemas, ocasionados por factores como la autoconstrucción y malas prácticas, en dichos procesos [11]. Esto con el fin de buscar una mayor rentabilidad en menor tiempo, ignorando lo reglamentado en Colombia [12].

En la ciudad de Tunja, se han desarrollado varios estudios preliminares sobre microzonificación sísmica. Entre ellos, destacan los planteados por el Instituto Geográfico, Universidad Javeriana y Consultoría Colombiana [6]. Del mismo modo, son de importancia la evaluación de la acción sísmica en la ciudad desarrollada por Molina y Alfaro [13] y los estudios de vulnerabilidad sísmica realizados por Agudelo y Martín [14]. A nivel nacional, cabe mencionar el trabajo de investigación de Villalba y González [15]. Mientras que, internacionalmente, los trabajos de Cubas y Rangel [16] y Martínez [17] son fundamentales. En ellos se presenta el interés por caracterizar el crecimiento de las ciudades y por identificar el tipo de estructuras existentes y la vulnerabilidad de las viviendas ante fenómenos naturales [18].

En el mismo orden, una investigación desarrollada por la Universidad Politécnica de Valencia en España evalúa los posibles daños de edificaciones ante amenazas naturales mediante SIG [19].
El procesamiento de imágenes satelitales y herramientas sig sirven de apoyo en estudios que buscan inventariar y caracterizar las construcciones de una ciudad [20], contribuyendo en la toma de decisiones. Este tipo de estudios son herramientas de planificación territorial que buscan identificar las edificaciones con sistemas estructurales no adecuados para soportar los sismos [21]. Así, las bases de datos de tipología estructural ayudan a evitar, prevenir y mitigar las consecuencias frente a un eventual sismo.

En el caso particular de Colombia, en la mayoría de ciudades no se conocen estudios recientes de tendencias y características del crecimiento urbano. Adicionalmente, en Tunja no se han caracterizado las edificaciones en la zona de desarrollo mediante imágenes satelitales. Esta falta de información puede propiciar problemas urbanísticos y de planeación del territorio ante un acelerado crecimiento urbano. En la última década, la ciudad de Tunja ha tenido un gran desarrollo arquitectónico y urbanístico gracias a la inversión de empresas privadas que han visto en la ciudad un potencial para la realización de nuevos proyectos comerciales. Principalmente, con planes de vivienda unifamiliar y multifamiliar [22].

Según el Instituto Geográfico Agustín Codazzi (IGAC), citado por Serrato y Perdomo [23], el incremento en los predios urbanos y en su área construida hacen de la ciudad una de las de mayor potencial en materia de inversión en el país. Por ello, es necesario representar las tendencias de crecimiento mediante cartografía digital. Una opción para la captura y administración de dicha cartografía son los sIG. Estos se caracterizan por contener información gráfica representada por vectores (puntos, líneas o polígonos), a la cual se asocia información descriptiva (números, textos, fechas, etc.), conocida como tabla de atributos [24].

A nivel mundial, se evidencia el uso de los sIG para dar solución a problemáticas de planeación de la tierra [24]. Reina et al. [25] presentan un ejemplo en donde se analizan áreas de riesgo mediante SIG y fotografías satelitales. Los SIG facilitan el manejo de la información para determinar zonas vulnerables en las ciudades. Por su parte, López y 
Plata [26] muestran una utilidad de clasificación de imágenes, analizando cambios en la cobertura del suelo como resultado de procesos de expansión urbana. Observando así la variación del suelo urbano en el tiempo como consecuencia de factores característicos de la ciudad de México.

Para el desarrollo de esta investigación, se eligieron imágenes que abarcan desde el año 1997. Posteriores a la Ley 388 de 1997, la cual articula los planes de desarrollo, la forma de zonificar el suelo urbano, suburbano y rural y los programas de preservación y conservación de los recursos naturales [27]. Se estableció el 2016 como el año final, previo al inicio de la investigación. Finalmente se analizó la información obtenida de la evaluación de construcciones localizadas sobre la zona de desarrollo. Dicha información proviene de visitas a edificaciones en las cuales se caracterizan sus condiciones de diseño y construcción. Específicamente, se estudiaron los sistemas estructurales (pórticos, muros de carga, etc), descritos en la sección A.3.2.1 de la Norma Sismo Resistente (NSR-10) que permiten resistir las fuerzas sísmicas y disipar la energía. En la figura 2, se aprecian algunos ejemplos de sistemas estructurales.
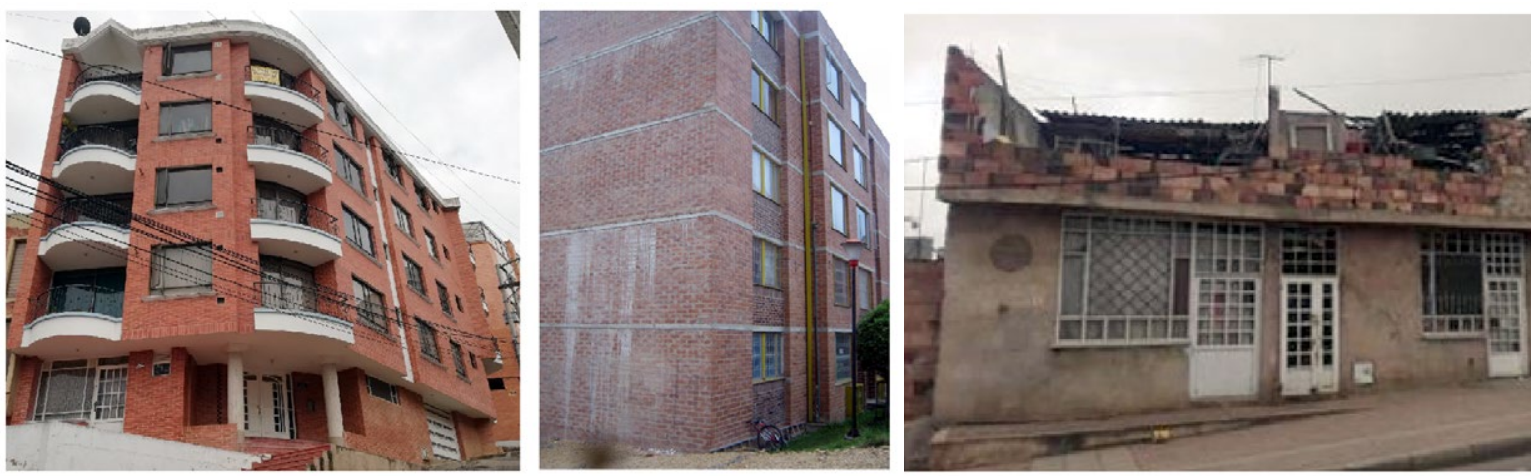

Figura 2. Sistemas estructurales. Pórticos (izquierda), muros de carga en mampostería confinada (medio) y muros de carga en mampostería no reforzada (derecha).

Fuente: elaboración propia.

También, se evaluó la calidad del diseño (buena, regular o mala), la cual se establece según la sección A.10.2.2.1 de la NSR10 teniendo en cuenta aspectos como la tecnología existente en la época de construcción, registros de interventoría, ensayos, distribución irregular de masa o de rigidez y ausencia de elementos estructurales que puedan afectar el comportamiento de la edificación frente a las solicitaciones de carga [12]. La estructura del documento presenta los participantes en la investigación, los recursos utilizados y la metodología desarrollada, a partir de la cual se muestran los resultados obtenidos y las conclusiones más relevantes.

\section{Materiales y métodos}

\subsection{Participantes}

La investigación fue liderada por el grupo de investigación en Ingeniería Civil y Ambiental (INVICA), de la Facultad de Ingeniería Civil de la Universidad Santo Tomás, seccional Tunja. Dentro de la etapa de toma de datos de tipología estructural en campo, participan investigadores pertenecientes al grupo. También contó con la activa participación de las juntas de acción comunal y de los habitantes de las edificaciones evaluadas. 


\subsection{Instrumentos y materiales}

Los siguientes son los materiales, instrumentos de adquisición y procesamiento de datos para el desarrollo de la investigación.

Para generar la zona de desarrollo de edificaciones 1997-2016, se procesaron dos imágenes satelitales:

- Landsat 5 del sensor Thermal Infrared Sensor (TIRs), adquirida el 13 de diciembre de 1997

- Landsat 8 combinada de los sensores Operational Land Imager (OLI) y TIRs, adquirida el 16 de enero de 2016.

La elección de imágenes de sensores de la constelación Landsat se debió, principalmente, a la facilidad de accesibilidad a las imágenes obtenidas del United States Geological Survey (USGs), transformando las bandas espectrales originales. El estudio se realizó a nivel general de acuerdo con la escala que proporcionan las imágenes Landsat. El uso de imágenes de mejor resolución espacial, como las RapidEye, proporciona un nivel semidetallado, lo cual mejoraría la precisión. Se empleó una base de datos geográfica con información vectorial (predios y construcciones) del municipio de Tunja, proveniente de la Modificación Excepcional del Plan de Ordenamiento Territorial (мерот), la cual se complementó con información catastral de datos abiertos del IGAC.

La información de tipología estructural se generó a partir de encuestas realizadas a viviendas de la ciudad de Tunja del 2017 al 2019. Se estableció el tamaño de muestra de forma no probabilística, teniendo en cuenta las características de la información mediante la cual se busca evaluar edificaciones de sectores, estratos y ubicaciones variadas y representativas de la ciudad. Al sobreponer la base de datos geográfica con la zona de desarrollo de construcciones establecida, se observan 36332 edificaciones en dicha zona. Para el presente estudio, fueron evaluadas 8783 localizadas en 43 barrios. Lo que representa una muestra del $24 \%$ del total de edificaciones.

\subsection{Procedimiento}

Para determinar las zonas donde se desarrollaron nuevas edificaciones (1997-2016), se procesaron y clasificaron las imágenes de las misiones satelitales Landsat 5 y Landsat 8, generando su clasificación a partir de la respuesta espectral de los píxeles. Esta es característica en función de la cobertura o el uso de suelo presente en el momento de la captura de la imagen. Un píxel que representa una zona edificada, posee un valor digital diferente a uno que representa una zona verde o sin edificación. Para la clasificación, se utilizó el método de aprendizaje semiautomatizado Random Forest, el cual genera buenos resultados para la identificación de zonas edificadas [28].

El método maneja puntos de entrenamiento en los que se señalan lugares edificados sobre las imágenes a partir de los cuales se realiza la clasificación sobre toda la imagen [29]. Con lo anterior, se obtienen las zonas construidas en 1997 y 2016. En ese orden de ideas, se identificó el cambio de usos como la cobertura vegetal y el suelo descubierto hacia zona urbanizada, donde se presenta el desarrollo de edificaciones. Para una mejor identificación de cambios fue necesario realizar correcciones radiométricas y atmosféricas, debido a procesos de absorción y dispersión ocasionados por las partículas en suspensión presentes en la atmósfera durante la toma de las imágenes [30].

Posteriormente, se combinaron las bandas y se calcularon los índices espectrales que generan imágenes que resaltan coberturas importantes para el estudio; como cambios de actividad fotosintética en el Índice de Vegetación Ajustado del Suelo, SAVI por sus siglas en inglés, [31] o áreas urbanizadas en el Índice de Diferencia Normalizada Edificada (NDBI) [32].Una vez localizada el área de nuevas edificaciones durante el periodo de estudio, se sobrepuso la capa de construcciones con información de tipología estructural (producto de visitas a campo), con el fin de analizar las características de las edificaciones en la zona de desarrollo.

Con base en referentes teóricos de tipología estructural, se definieron las características de las edificaciones a ser tenidas en cuenta. En el presente estudio, se analizó el sistema estructural y la calidad del diseño. Se definió la encuesta para evaluar la tipología de las edificaciones en zonas de la ciudad con características variadas en cuanto a ubicación, estrato y destino económico. Igualmente, 
para el periodo de estudio, fue verificado que estas se encontraran dentro de la zona de nuevas construcciones distribuidas sobre los barrios en los que se contaba con acceso para la realización de la encuesta. Lo anterior, permitió evaluar edificaciones en zonas que fueran muestras representativas. Posteriormente, se socializó el proceso ante las autoridades y las juntas de acción comunal de cada barrio, lo que facilitó la toma de información.

La información producto de las encuestas fue tabulada en hojas de cálculo que generaron tablas con datos de tipología estructural. Estas incluyen el número catastral de cada edificación evaluada. En el SIG, las edificaciones se representaron mediante un vector de tipo polígono que cuenta dentro de su tabla de atributos con el número catastral. Este identifica cada edificación mediante un código con información del departamento, municipio, tipo de edificación (urbana o rural), sector, manzana y número de predio al que pertenece. Usando herramientas SIG se relacionó el código catastral presente en las tablas con el mismo código que hace parte de los atributos de los polígonos de las edificaciones en la base de datos geográfica. De esta manera, se unieron todos los datos de las encuestas hechas a las edificaciones con las tablas de atributos de la base geográfica para generar mapas de distribución espacial de tipología estructural, como el sistema estructural y la calidad de las construcciones.

Finalmente, a partir de la imagen clasificada que define la zona edificada para el periodo de estudio, se analizó la tipología estructural de las edificaciones construidas sobre dicha zona. Determinando el número de edificaciones encontradas en función de la calidad de la construcción y del sistema estructural. La metodología se aprecia en la figura 3.

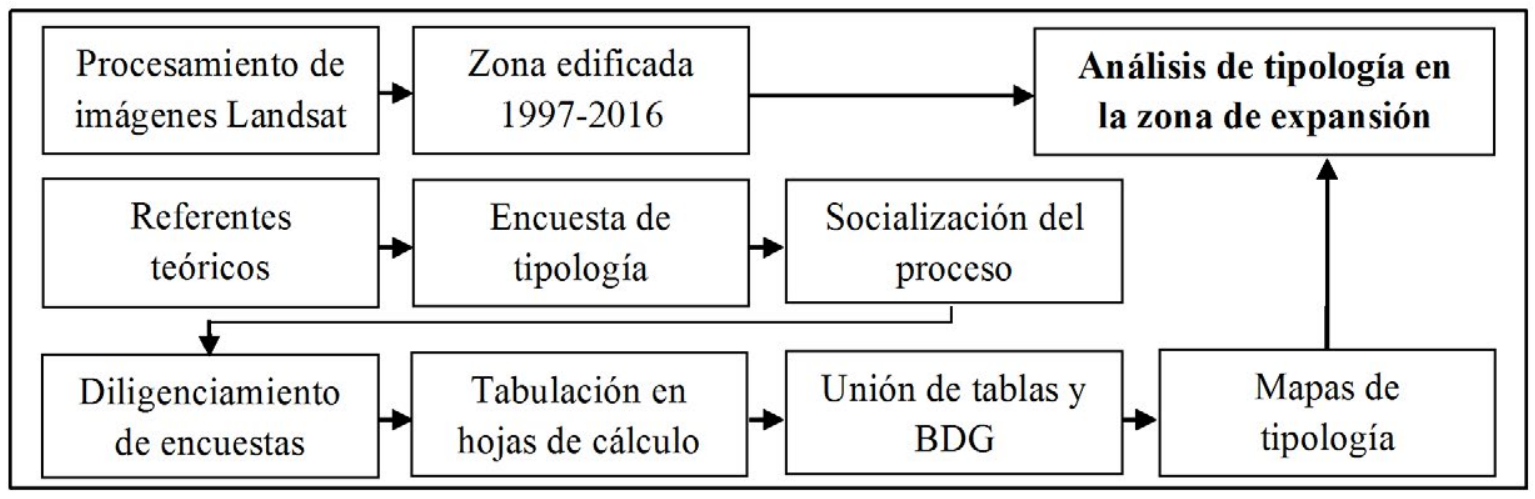

Figura 3. Metodología.

Fuente: elaboración propia.

\section{Resultados y discusiones}

Se obtienen los siguientes resultados del desarrollo del proyecto:

\subsection{Zona edificada 1997-2016}

Luego de procesar las imágenes satelitales para la zona urbana de la ciudad, se obtuvieron las zonas edificadas en 1997 y en 2016, respectivamente. A partir de esta información, se estableció la zona de edificaciones construidas entre 1997 y 2016. En la figura 4 se aprecian las edificaciones en las que se evaluó la tipología estructural, como muestra representativa de la zona de estudio. 

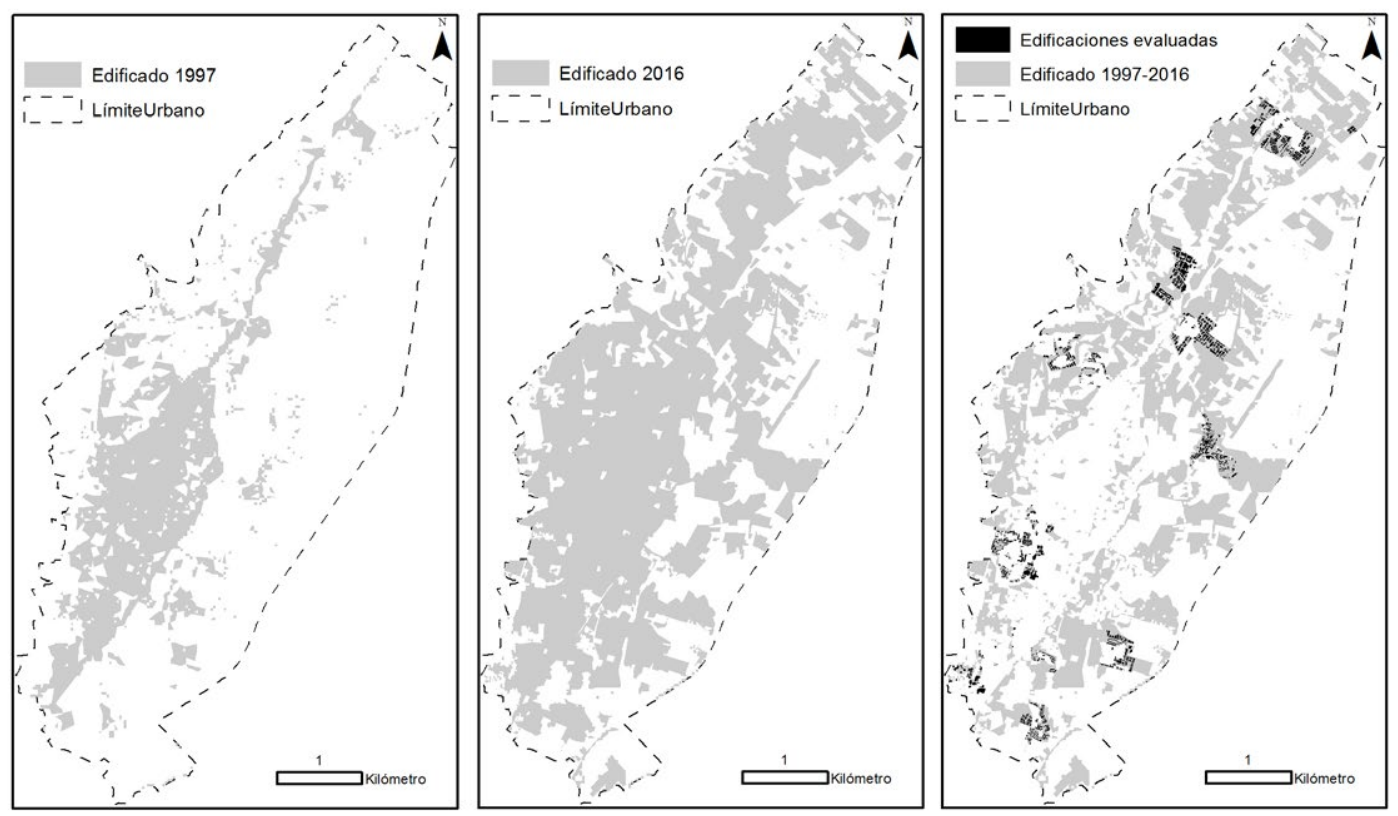

Figura 4. Zonas edificadas en 1997 (izquierda), en 2016 (medio) y edificadas entre 1997 y 2016 (derecha).

Fuente: elaboración propia.

\subsection{Mapas de tipología estructural}

Usando el sig, se agregó la información de tipología estructural recopilada en las encuestas, como atributos de la capa de edificaciones de la BDG. Con ello, se generaron mapas de tipología estructural que muestran la distribución espacial de características de las edificaciones. Entre ellas, se encuentran el sistema estructural y la calidad del diseño. En la figura 5 se aprecian los mapas temáticos de las dos características mencionadas para un barrio de la zona de estudio. El mapa de sistema estructural discrimina el tipo de muro de carga (mampostería confinada o no reforzada).
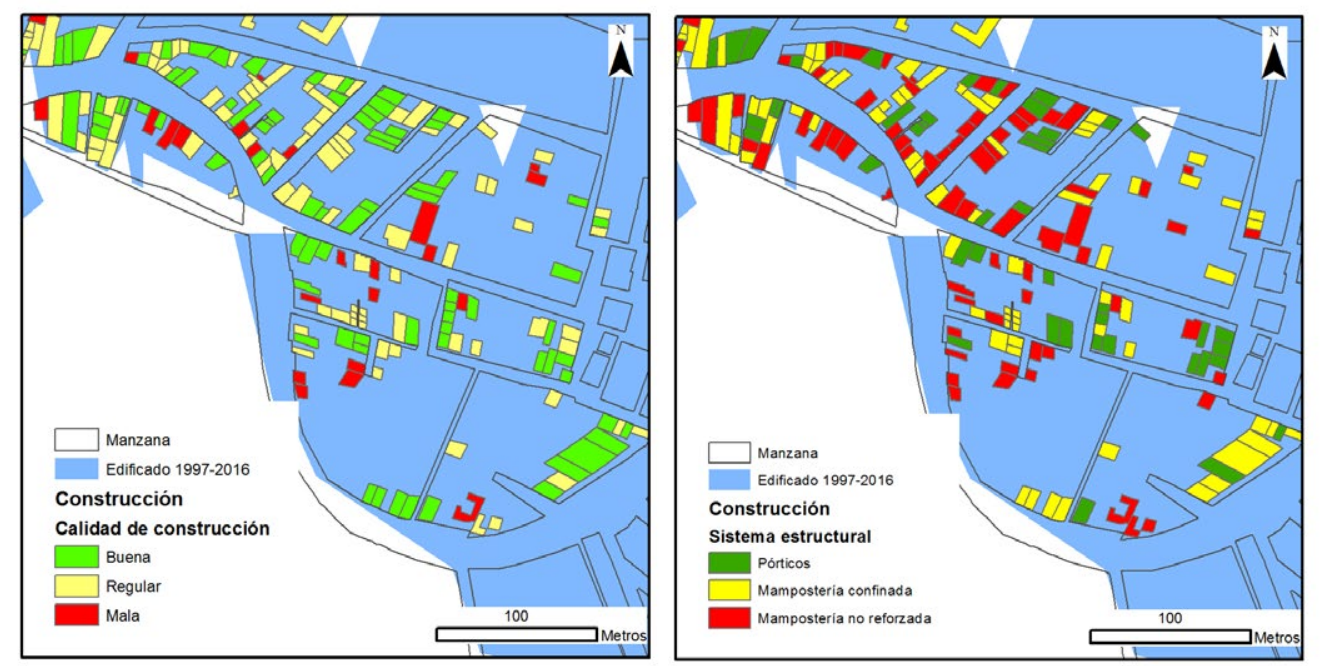

Figura 5. Mapas de tipología. Calidad de diseño de construcción (izquierda) y sistema estructural (derecha). Fuente: elaboración propia. 


\subsection{Tipología estructural sobre la zona de expansión}

En la figura 6 se aprecian los resultados de tipología estructural con respecto a calidad de diseño (arriba) y sistema estructural (abajo) para las 8783 edificaciones sobre la zona de expansión:
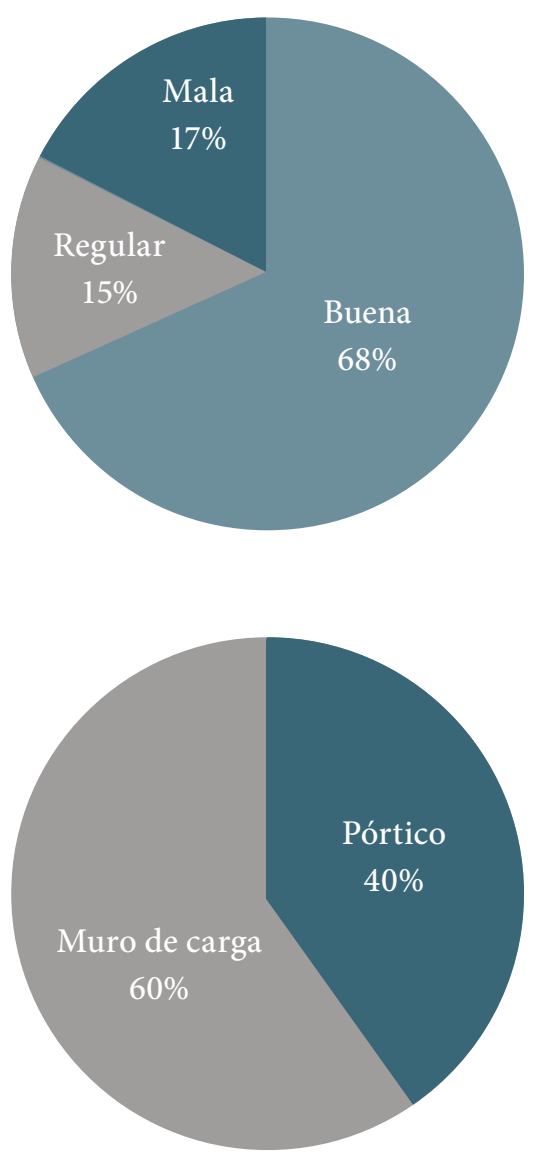

Figura 6. Resultados de Tipología: calidad de diseño de construcción (izquierda) y sistema estructural (derecha). Fuente: elaboración propia.

La figura 6 (abajo) muestra que el $60 \%$ de los sistemas estructurales corresponden a muros de carga. En las encuestas se especificó el tipo de muro de carga presente en las edificaciones evaluadas (figura 7).

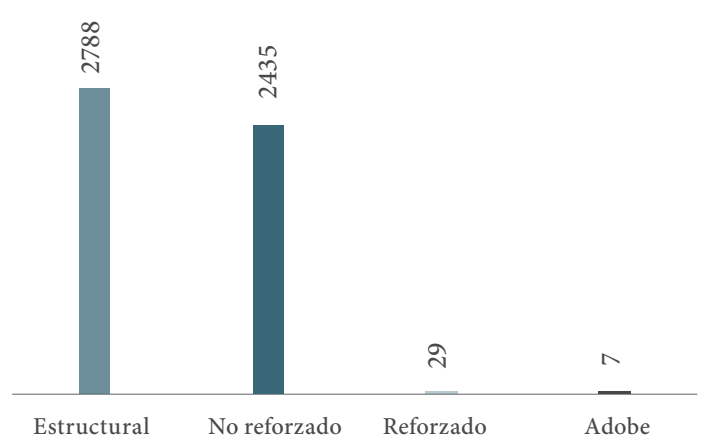

Figura 7. Tipo de muro de carga.

Fuente: elaboración propia.

\subsection{Discusión}

En la ciudad de Tunja se aprecia un crecimiento importante en área construida durante el periodo 1997-2016, el cual genera un desarrollo urbano, social y económico. Por ende, se requiere de instrumentos de planificación territorial y control urbano; como la evaluación tipológica de edificaciones frente a normas de diseño y construcción. Cuando se atiende la demanda de vivienda sin atender la normativa de diseño y construcción, se aumenta el riesgo de desastres.

La georreferenciación de datos como la calidad de diseño y el sistema estructural son útiles para las entidades que conforman el Sistema Nacional para la Prevención y Atención de Desastres. Pues contribuyen a la creación de planes de contingencia en caso de eventos sísmicos, así como a la planeación y creación de sistemas de alerta temprana de las construcciones de la ciudad, planes de ordenamiento, estudios de vulnerabilidad y microzonificación sísmica en la ciudad. Por esta razón, es importante apropiar el conocimiento de las comunidades para utilizarlo en las construcciones existentes o por construir. Mitigando las pérdidas humanas y materiales ante posibles desastres.

Parte de los resultados obtenidos en la presente publicación pueden compararse con investigaciones como la de Serrato y Perdomo [23], en la que se presenta un estudio multitemporal de crecimiento 
urbano para la ciudad de Tunja, usando metodologías diferentes. El estudio determina el área construida en el municipio de Tunja. En la tabla 2 se comparan los resultados de dicho estudio con los calculados por esta investigación. Se aprecia una similitud en los datos obtenidos, teniendo en cuenta las diferencias metodológicas. Esto, dado que el estudio de referencia se realizó a partir de fotointerpretación e incluyó las áreas de vías, mientras que este artículo clasifica las imágenes por medio de un método semiautomatizado.

Tabla 2. Área construida en la zona urbana de Tunja.

\begin{tabular}{|c|c|c|c|c|}
\hline Estudio & \multicolumn{2}{|c|}{$\begin{array}{l}\text { Tunja, valor del } \\
\text { suelo, } 2015\end{array}$} & \multicolumn{2}{|c|}{ Presente estudio, 2017} \\
\hline Año & 1995 & 2013 & 1997 & 2016 \\
\hline Área & & & & \\
\hline $\begin{array}{l}\text { construida } \\
(\mathrm{Km} 2)\end{array}$ & 5,3 & 14,1 & 4,8 & 12,6 \\
\hline
\end{tabular}

Fuente: elaboración propia, creada a partir de "Una mirada al pasado de Tunja-2015. Tunja valor del suelo", 2018 [16].

Continuar con el estudio y aplicarlo en otras ciudades permitiría establecer las tendencias de crecimiento y de uso de sistemas estructurales, así como también determinar la calidad del diseño de las edificaciones. Se debe continuar con la recopilación de información de toda la ciudad y actualizar la que se tiene, ya que las edificaciones evolucionan constantemente.

\section{Conclusiones}

Los resultados obtenidos de la expansión urbana para la ciudad de Tunja reflejan las particularidades y tendencias en la dinámica inmobiliaria que la ciudad ha presentado en los últimos años. De acuerdo con la investigación, en 20 años, Tunja estuvo cerca de triplicar su área edificada. Pasando de 4,8 $\mathrm{Km}^{2}$ en 1997 a 12,6 $\mathrm{Km}^{2}$ en 2016.

Se observa que en Tunja la mayoría de las edificaciones construidas durante el periodo 1997-2016 (68\% de la muestra evaluada) presentan una calidad del diseño buena, teniendo en cuenta parámetros establecidos por la norma NSR-10. Lo anterior es coherente con la dinámica predominante de construcción en la ciudad, la cual presenta su mayor volumen en proyectos formales de vivienda y servicios con prácticas adecuadas de construcción.

Los sistemas estructurales predominantes sobre la zona de estudio corresponden a muros de carga (60\%), principalmente, no reforzados, confinados y muros reforzados, frente a sistemas de pórtico (40\%). En su mayoría, se pueden considerar condiciones de calidad buenas. Sin embargo, la implementación de políticas estrictas de control urbano e, incluso, de capacitación a la comunidad de la construcción podrían contribuir a la labor de este sector.

\section{Referencias}

[1] S. D. Pinto, A. Arce y E. Gómez, "Proceso de urbanización en Colombia," Análisis Geográficos, vol. 15, n. ${ }^{\circ} 1$, pp. 256-257, 1988.

[2] F. A. Muñoz, "La Administración de Tunja a través del siglo $X X$," tesis de maestría, Facultad de Artes, Universidad Nacional de Colombia, Bogotá D.C., Colombia, 2014. [Internet]. Disponible en: http://www.bdigital. unal.edu.co/46574/1/03391234.2014.pdf.[3]

[3] A. Hidalgo, "El papel de la vivienda en la configuración urbana de las periferias: caso de Tunja-Colombia 1907-2007," en Cuadernos de vivienda y urbanismo, vol. 1, n. ${ }^{\circ}$ 1, pp. 12-43, 2008. [Internet]. Disponible en: http://revistas.javeriana.edu.co/index.php/cvyu/issue/ view/1182. [Accedido: 2017, dic. 10].

[4] E. Rodríguez, M. Sánchez y C. Sainea. "Metodología para la respuesta dinámica del subsuelo en la Microzonificación sísmica de la ciudad de Tunja.” En III Seminario Internacional de Ingeniería Sísmica y Geotecnia, Tunja, Boyacá, 2015. [En línea]. Disponible en: http:// www.uptc.edu.co/export/sites/default/eventos/2013/ cf/siisg/memorias/documentos/2_16Metodologia_ respuesta.pdf [Accedido: 2021, sept. 9].

[5] O. Ramírez, "Determinación de efectos de sitio a nivel preliminar para la ciudad de Tunja” en IX Congreso Colombiano de Geotecnia, 2002.

[6] Instituto Geográfico Universidad Javeriana y Consultoría Colombiana, Microzonificación sísmica preliminar de Tunja, Bogotá: Instituto Geográfico Universidad Javeriana y Consultoría Colombiana, 2000 [En línea]. Disponible en: https://www.monografias.com/trabajos-pdf4/microzonificacion-sismica-preliminar-tunja/ microzonificacion-sismica-preliminar-tunja.pdf. [Accedido: 2017, ag. 3]. 
[7] M. Rincón, (2009). "Procesos de transformación urbana: el caso de Tunja 1900-2005," Perspectiva Geográfica. [Internet]. Vol. 14, pp. 13-44. Disponible en: http:// revistas.uptc.edu.co/index.php/perspectiva/article/ view/1716.

[8] Organización para las Naciones Unidas, ONU-Habitat y la Universidad de Michigan evalúan los marcos legales $y$ de políticas de Colombia, Bogotá: onu Habitat, 2020. [Internet]. Disponible en: https://onuhabitat.org.mx/ index.php/onu-habitat-y-la-universidad-de-michigan-evaluan-los-marcos-legales-y-de-politicas-de-colombia. [Accedido: 2020, sept. 3].

[9] E. Gielen, G. Riutort-Mayol, J. S. Palencia-Jiménez et al., "An urban sprawl index based on multivariate and Bayesian factor analysis with application at the municipality level in Valencia," Environment and Planning B: Urban Analytics and City Science, vol. 45, n. ${ }^{\circ}$ 5, pp. 888-914, 2017.

[10] Naciones Unidas, "Ciudades y comunidades sostenibles", en Informe de los objetivos de desarrollo sostenible. Nueva York: United Nations Publications, 2019, pp. 44-45.

[11] M. M. Montesinos, Formalización de procesos constructivos para reducir vulnerabilidad sísmica de las viviendas autoconstruidas del PPJJ Los Rosales, Trujillo, Perú: Universidad César Vallejo, 2019, pp. 105. [Internet]. Disponible en: https://repositorio.ucv.edu. pe/bitstream/handle/20.500.12692/45746/Montesinos_NMM-SD.pdf?sequence $=8 \&$ isAllowed $=y$. [Accedido: 2021, en. 24].

[12] Asociación de Ingeniería Sísmica, Reglamento colombiano de construcción sismo resistente NSR-10, vol. Tomo 2, Bogotá: AIs, 2010, pp. 67-89.

[13] G. P. Molina y A. J. Alfaro, (2009, dic.). "Evaluación de la acción sísmica para Tunja Colombia," Ciencia e Ingeniería Neogranadina. [Internet]. Vol. 19, n. ${ }^{\circ}$, pp. 17-28. Disponible en https://doi.org/10.18359/rcin.287.

[14] A. Agudelo y M. Castro, Estudio de vulnerabilidad sísmica de la ciudad de Tunja, trabajo de pregrado, Universidad Pedagógica y Tecnológica de Colombia, Tunja, 1999.

[15] M. A. Villalba y M. F. González, Evaluación de la vulnerabilidad sísmica para un sector de la comuna 2 del municipio de Dosquebradas-Risaralda-Colombia, Bogotá: Universidad Militar Nueva Granada, 2020, pp. 16, [Internet]. Disponible en: https://repository.unimilitar.edu.co/handle/10654/37969. [Accedido: 2021, febr. 10].

[16] H. Cubas y G. L. Rangel, "Vulnerabilidad Sísmica de los Centros de Salud del Distrito de Jaén," Jaén, Perú: Universidad Nacional de Jaén, 2020, pp. 160 [Internet].
Disponible en: http://repositorio.unj.edu.pe/handle/ UNJ/152. [Accedido: 2021, mzo. 7].

[17] S. Martínez, "Evaluación de la vulnerabilidad sísmica urbana basada en tipologías constructivas y disposición urbana de la edificación. Aplicación en la ciudad de Lorca, región de Murcia”, tesis Ph.D., Universidad Politécnica de Madrid, España, 2014.

[18]J. Palencia, "La necesidad de cambios en la planificación territorial ante el riesgo de inundaciones. El ejemplo de la Comunidad Valenciana." Revista de Obras Públicas: Órgano profesional de los ingenieros de caminos, canales y puertos, vol. 164, n. ${ }^{\circ} 3587$, pp. 82-95, 2017.

[19] I. Cantarino, F. J. Torrijo, S. Palencia et al., "Assessing residential Building Values in Spain for Risk Analyses-Application to the Landslide Hazard in the Autonomous Community of Valencia," Natural Hazards and Earth System Sciences, vol. 14, n. ${ }^{\circ}$ 11, pp. 30153030, 2014.

[20]H. Miura y S. Midorikawa, “Updating GIs Building Inventory Data Using High-Resolution Satellite Images for Earthquake Damage Assessment: Application to Metro Manila, Philippines," Earthquake Spectra, vol. 22, n. ${ }^{\circ} 1$, pp. 151-168, 2006.

[21] A. Albareda, J. Maristany, N. García et al., "Estudio, diagnosis y caracterización de sistemas estructurales en un conjunto de edificios históricos de Skikda, Argelia”. en XII Congresso International Sobre Patologia e Reabilitacao de Estruturas, Feup, Porto, Portugal, pp. 1-18. Faculdade de Engenharia da Universidade do Porto, 2016.

[22]J. Díaz. Diagnóstico de impactos ambientales de proyectos de viviendas VIS y VIP en la ciudad de Tunja, 2021. Disponible en: https://repository.ucatolica.edu. co/bitstream/10983/25947/1/TRABAJO_DE_GRADO_JAVIER_FELIPE_DIAZ_MALDONADO\%20 \%281\%29.pdf

[23] P. K. Serrato y A. Perdomo, (2018, abr.). "Una mirada al pasado de Tunja-2015. Tunja valor del suelo," Análisis geográficos. [Internet]. n. ${ }^{\circ}$ 52, pp. 1-179. Disponible en: https://www.researchgate.net/publication/324783447_Una_mirada_al_pasado_de_Tunja-2015

[24] A. Moreno, Sistemas y análisis de la información geográfica, 2 ed., Madrid: Alfaomega, 2013, pp. 3-6.

[25] A. E. Reyna, D. E. Moreira, A. N. Bonilla et al., (2020, dic.). "Asentamientos humanos en zonas susceptibles a riesgos por inundación y deslizamiento de la ciudad de Portoviejo," Revista San Gregorio. [Internet]. vol. 1, n. ${ }^{\circ} 43$, pp. 109-123. Disponible en: http://scie- 
lo.senescyt.gob.ec/scielo.php?script=sci_arttext\&pi$\mathrm{d}=$ S2528-79072020000400109.

[26] V. H. López y W. Plata, (2009, abr.). "Análisis de los cambios de cobertura de suelo derivados de la expansión urbana de la Zona Metropolitana de la Ciudad de México, 1990-2000," Investigaciones geográficas. [Internet]. n.o 68, pp. 85-101. Disponible en: http:// www.scielo.org.mx/scielo.php?script=sci_arttext\&pi$\mathrm{d}=\mathrm{S} 0188-46112009000100007 \& \operatorname{lng}=\mathrm{es} \& \mathrm{nrm}=\mathrm{iso}$

[27] L. Molina López y C. Albarracín Granados (2008, abr.). "Los instrumentos de planeamiento urbanístico en la ley 388 de 1997," ACE: architecture, city and environment. [Internet]. n. ${ }^{\circ}$ 7, pp. 67-78. Disponible en: https://raco.cat/index.php/ACE/article/view/185870

[28]N. del Toro-Espín, F. Gomariz-Castillo, F. Cánovas-García et al., "Comparación de métodos de clasificación de imágenes de satélite en la cuenca del río Argos (Región de Murcia)," Boletín de la Asociación de Geógrafos Españoles, n. ${ }^{\circ}$ 67, pp. 327-347, 2015.

[29]L. Breiman, "Random Forest", Machine Learning, vol. 45, no. 1, pp. 5-32, 2001.

[30] G. Chander, B. L. Markham y D. L. Helder, (2009). "Summary of Current Radiometric Calibration Coefficients for Landsat MSs, TM, ETM+, and EO-1 ALI Sensors," Remote sensing of environment. [Internet]. Vol. 5, n. ${ }^{\circ} 113$, pp. 893-903. Disponible en: https://doi. org/10.1016/j.rse.2009.01.007. [Accedido: 4 diciembre 2017].

[31] P. P. Rhyma, K. Norizah, O. Hamdan et al., (2020). "Integration of Normalised Differece Vegetation Index and Soil-Adjusted Vegetation Index for Mangrove Vegetation Delineation," Remote Sensing Applications: Society and Environment. [Internet]. Vol. 17, Disponible en https://doi.org/10.1016/j.rsase.2019.100280.

[32] W. García y X. E. Rivera, Islas de calor urbano: efecto del crecimiento no planificado del área urbana de la Ciudad de Jaén, Cajamarca (1995-2015), Jaén, Perú: Universidad Nacional de Jaén, 2020, pp. 160. [Internet]. Disponible en: http://repositorio.unj.edu.pe/ handle/UNJ/278 [Accedido: 7 de marzo 2021]. 